\title{
KINERJA KEUANGAN SEKTOR INDUSTRI PASAR MODAL INDONESIA DALAM ERA EKONOMI PASIFIK
}

\author{
David Paul Elia Saerang dan Ventje Ilat \\ Email : d_saerang@lycos.com
}

\begin{abstract}
By point of view of economics, Indonesia is one of most countries, who have strong fundamental factors because it was arose from global financial crisis in period of 1997 till 2008. By this fact, in world's perception, Indonesia as a one country who have strong potential for era of 2020 and 2030, which is equal to others countries. The economic growth is also connecting with investment condition in capital market, and it is indicate that the role of investors are very important for economic growth acceleration in Indonesia.

This study took 36 companies as sample in period of 2009 till 2012 and using multiple regression analysis for hypothesis testing. The results of analysis are show that, business cycle has not significant effect for share price, but partially, debt capacity, profitability, and market price ratio have significant effect for share price.
\end{abstract}

Key Words : share price, business cycle, debt capacity, profitability, market price ratio.

\section{Pendahuluan}

Dalam era ekonomi pasifik, Indonesia merupakan salah satu wilayah terbesar yang pertumbuhan ekonominya sedang meningkat. Keterpurukan Indonesia di masa lalu dengan himpitan persaingan dari negara Asia lainnya seperti Malaysia, Singapura, Filipina dan Thailand, ternyata tidak menyurutkan semangat Indonesia untuk mempercepat laju pertumbuhan ekonomi. Kebijakan-kebijakan pemerintah dimasa lalu untuk pembangunan berorientasi daratan (land based development) yang menjadi faktor lambatnya pertumbuhan ekonomi Indonesia ternyata berbalik menjadi senjata ampuh untuk pembangunan ekonomi dimasa sekarang sebagai pilar infrastruktur yang kuat.

Dalam beberapa pengamatan secara ekonomi, Indonesia merupakan salah satu negara yang memiliki faktor fundamental yang kuat karena bangkit kembali dari krisis ekonomi tahun 1997 dan mampu bertahan dalam krisis keuangan global di tahun 2008. Hal ini menyebabkan Indonesia dipandang dalam mata dunia sebagai negara yang memiliki kekuatan potensial pada era 2020 dan 2030, setara dengan negara-negara yang memiliki kekuatan ekonomi maju.

Dalam Pidato Kenegaraan pada 16 Agustus 2012, Presiden Susilo Bambang Yudhoyono mengemukakan, di tengah ketidakpastian perkembangan ekonomi global, kinerja ekonomi Indonesia masih dapat menunjuklan kinerja yang cukup baik. Pada 2011, di saat beberapa negara lain mengalami perlambatan atau bahkan pertumbuhan negatif, pertumbuhan ekonomi Indonesia mencapai 6,5 persen. Kinerja pertumbuhan ekonomi Indonesia sebesar itu ditopang permintaan domestik yang cukup kuat. Tercatat, pertumbuhan ekonomi nasional pada triwulan I/2012 mencapai 6,3 persen, pada triwulan II sedikit meningkat 6,4 persen, dan pertumbuhan ekonomi Indonesia pada 2012 dapat dipertahankan pada kisaran 6,3 persen.

Menurut Asian Development Bank (ADB) dalam laporan ekonomi utama tahunan ADB, Asian Development Outlook ( $A D O 2013$ ) diperkirakan bahwa Indonesia akan tumbuh sebesar 6,4\% di 2013 dan melaju ke level 6,6\% di 2014, yang merupakan angka pertumbuhan tertinggi dalam 15 tahun terakhir. Proyeksi ini mengasumsikan konsumsi swasta akan menguat pada 2013, yang dipicu oleh meningkatnya lapangan pekerjaan, upah minimum ratarata, dan gaji pegawai negeri.

Pertumbuhan ekonomi ini juga tidak lepas dari iklim investasi yang terjadi dalam pasar modal sebagai tanda bahwa terdapat peran investor yang cukup signifikan dalam mempercepat pertumbuhan ekonomi di Indonesia. Hal ini dapat terlihat dalam transaksi 
modal dan finansial yang mencatat kenaikan surplus yang cukup besar terutama didukung investasi langsung (PMA) dan arus masuk modal portofolio, baik dalam pasar saham maupun pasar obligasi, yang lebih tinggi dibandingkan dengan tahun sebelumnya. Atas perkembangan tersebut, cadangan devisa sampai dengan akhir Desember 2012 mencapai 112,78 miliar dolar AS, atau setara dengan 6,1 bulan impor dan pembayaran utang luar negeri Pemerintah.

ADO 2013 juga mencatat bahwa Indonesia tumbuh sebesar 6,2\% di 2012, sebagai hasil dari tingkat konsumsi domestik dan investasi yang terus menguat. Konsumsi swasta tumbuh sebesar 5,3\%, yang merupakan angka tertinggi dalam empat tahun terakhir dan berkontribusi hampir setengah dari total pertumbuhan produk domestik brutto (PDB) dari segi pembelanjaan. Hal ini didorong oleh semakin banyaknya lapangan pekerjaan, meningkatnya gaji, dan rendahnya tingkat inflasi. Sementara itu upaya Pemerintah untuk mendorong investasi sektor publik dapat dilihat dari semakin meningkatnya belanja modal di sektor ini.

Sementara itu, investasi meningkat menjadi 9,8\% pada 2012, yang didorong oleh membaiknya iklim investasi, rekor pertumbuhan ekonomi yang kuat beberapa tahun terakhir, dan peningkatan kredit. Sebagai hasilnya, rasio investasi terhadap PDB meningkat menjadi $33,2 \%$ dalam periode setidaknya 20 tahun terakhir. Sementara itu upaya Pemerintah untuk mendorong investasi sektor publik dapat dilihat dari semakin meningkatnya belanja modal di sektor ini.

Selain itu, ekspor diprediksi akan kembali meningkat pada tahun 2013 ini, yang antara lain didorong oleh menguatnya pertumbuhan di Republik Rakyat China (RRC) dan negaranegara lain. Angka ini diproyeksikan akan terus meningkat pada 2014, karena semakin membaiknya peluang pertumbuhan di negara-negara industri lain. Angka kemiskinan menurun sebanyak 0.7 poin menjadi 11,7\% dalam 12 bulan sampai dengan September 2012. Perbaikan ini disebabkan oleh meningkatnya upah bagi para pekerja sektor pertanian dan konstruksi, serta pendapatan petani yang makin tinggi. Kualitas pekerjaan pun terus mengalami pertumbuhan: Tahun lalu, terdapat 2,7 juta pekerjaan baru di sektor formal, sedangkan terjadi penurunan pekerjaan di sektor informal sebanyak 1,5 juta.

Sementara itu, tingkat inflasi rata-rata diprediksi akan berada pada tingkat wajar yaitu 5,2\% pada 2013 dan 4,7\% pada 2014. Proyeksi ini didasarkan pada asumsi tidak akan ada kenaikan harga bahan bakar dalam dua tahun mendatang. Angka inflasi akan menjadi tinggi apabila Pemerintah ingin mengurangi beban subsidi dengan menaikkan harga bahan bakar. Salah satu tantangan utama bagi pembangunan di Indonesia adalah bagaimana memastikan bahwa pertumbuhan ekonomi tersebut dirasakan oleh semua pihak. ADO 2013 mencatat bahwa meskipun pertumbuhan ekonomi selama enam tahun terakhir telah mengentaskan 6,4 juta orang dari kemiskinan, masih ada 29 juta masyarakat Indonesia yang hidup di bawah garis kemiskinan yang ditetapkan Pemerintah. Apabila terjadi penurunan tingkat pendapatan sedikit saja, maka akan ada 30 juta masyarakat Indonesia lainnya yang menjadi miskin.

Untuk menghadapi tantangan tersebut, perlu ada kebijakan yang terfokus pada usaha pengurangan kesenjangan, termasuk upaya berkesinambungan untuk memperbaiki infrastruktur publik, khususnya transportasi dan listrik. Lemahnya infrastruktur di daerah pedesaan dan kawasan timur Indonesia telah menghambat kegiatan ekonomi dan tumbuhnya lapangan pekerjaan baru.

Dalam kawasan kekuatan ekonomi di Asia Pasifik, Indonesia bersama dengan negara lainnya seperti Malaysia, dan Filipina diprediksi akan mendorong perkembangan Asia Timur dengan pertumbuhan mencapai 5,7 persen dan 5,8 persen pada 2014. Untuk 2012, tanpa mengikutsertakan China, kawasan berkembang Asia Tenggara ini tercatat bakal tumbuh 6,5 persen, atau meningkat 4,4 persen dari 2011.

Dalam konteks pasar modal, investasi saham dinilai mempunyai tingkat risiko yang lebih besar dibandingkan dengan alternatif investasi yang lain karena pendapatan yang diharapkan dari investasi pada saham bersifat tidak pasti dan sangat bergantung pada keadaan pasar. 
Dalam proses investasi, kadang perilaku dan psikologi investor sangat berperan penting dalam menghadapi risiko investasi tersebut. Dengan demikian preferensi investor terhadap risiko yang terkandung pada masing - masing jenis saham akan mempengaruhi volume perdagangan saham yang bersangkutan. Sebab itu dalam melakukan investasi dalam bentuk saham, investor harus melakukan analisis terhadap faktor yang dapat mempengaruhi kondisi perusahaan emiten, sehingga dapat meminimalisasi kerugian yang dapat timbul dari adanya fluktuasi pertumbuhan dan perkembangan emiten yang bersangkutan.

Stabilitas siklus bisnis dan komposisi kapasitas hutang atas modal sebagai salah satu bentuk manajemen modal, akan sangat diperhatikan oleh investor dalam rangka mengevaluasi kesanggupan perusahaan untuk memberikan dividen maupun memberikan keuntungan (capital gain) yang maksimal atas investasi yang ditanamkan oleh investor tersebut. Dalam hal ini, Bodie (2005), Jones (2004) dan Ross (2005) berpendapat bahwa, siklus bisnis dan kapasitas hutang dari sebuah badan usaha tersebut akan memicu reaksi investor pada pasar saham karena terkait dengan masalah risiko dan kompensasi investasinya.

\section{Tinjauan Pustaka}

\subsection{Harga Saham dan Pertumbuhan Ekonomi.}

Duca (2007) menyatakan bahwa, setidaknya terdapat 3 proposisi bagaimana harga saham akan berdampak langsung pada hasil sebuah perekonomian, yaitu :

First, it focuses on the impact that share prices have on the cost of capital, and is captured by a coefficient known as Tobin's $Q$, which is the ratio of the market value of current capital to the cost of replacement capital. When share prices are high, the value of the firm relative to the replacement cost of its stock of capital (Tobin's Q) is also high. Consequently, this leads to increased investment expenditure and thus to higher aggregate economic output as firms find it easier to finance investment expenditures. This occurs because investment would be easier as it would require a lower share offering in a situation of a high share price.

The second channel through which stock market performance may influence GDP was suggested by Modigliani (1971). His proposition operates through the impact that the wealth variable has on consumption. A permanent increase in security prices results in an increase in the individual's wealth holdings, and therefore in higher permanent income. Through the permanent income hypothesis, Modigliani postulated that intertemporally, consumers smoothen consumption in order to maximize their utility. An increase in permanent income will therefore enable consumers to re-adjust upwards their consumption levels in each period.

The third possibility through which stock prices impact output is referred to as the financial accelerator (Bernanke and Gertler, 1989; Kiyotaki and Moore, 1997). This channel focuses on the impact that stock prices have on firms' balance sheets. Due to the presence of asymmetric information in credit markets, the ability of firms to borrow depends substantially on the collateral they can pledge. The collateral value firms can offer increases in scenarios where their stock price value increases. As the collateral they can offer increases, higher credit can be raised, which in turn can be used for investment purposes and thereby triggers an expansion in economic activity.

Caporale et al (2004), berdasarkan hasil penelitian menemukan bahwa pasar modal yang telah berkembang dengan baik, dapat mempercepat laju pertumbuhan ekonomi dalam jangka waktu yang panjang. Sehingga berdasarkan hasil penelitian mereka, secara ilmiah dapat dikatakan bahwa pasar modal sebuah negara yang berfungsi dengan baik, dapat mempromosikan atau memberikan tanda bahwa adanya perkembangan ekonomi, yang 
pertumbuhannya disebabkan karena adanya akumulasi modal investasi yang cepat dan alokasi sumber daya yang lebih baik.

Sedangkan Sharma (2013), berpendapat bahwa, kekuatan makroekonomi memiliki pengaruh yang sistematis pada harga saham melalui aliran kas masa depan. Hubungan antara harga saham dan faktor makroekonomi, telah banyak dikaji dengan berbagai fluktuasi makroekonomi pada harga saham yang mempengaruhi nilai diskontonya. Pendapat yang sama diajukan oleh Boubakari dan Jin (2010), yang menyatakan bahwa pertumbuhan atas pasar modal dengan pertumbuhan ekonomi memiliki hubungan jangka panjang. Hal ini disebabkan karena likuiditas dari pasar modal akan membantu meningkatkan masa depan dari perekonomian.

Riman et. al. (2008), dalam hasil penelitiannya menyatakan bahwa pasar saham sangat signifikan dalam menentukan pertumbuhan ekonomi di Nigeria. Akan tetapi sangat disarankan perlu dilakukan penelitian atas hubungan sebab akibat yang bersifat searah gabungan pada saat faktor-faktor yang bersifat non finansial juga ikut berperan dalam perkembangan pasar saham di Nigeria. Hasil penelitian ini didukung oleh Ogboi \& Oladipo (2012), dengan objek negara yang sama yaitu Nigeria, dimana hasil penelitian menunjukkan bahwa terdapat hubungan sebab akibat yang searah antara pasar saham dan pertumbuhan ekonomi.

Hal yang lebih spesifik dinyatakan oleh Alam dan Udin (2009), bahwa tingkat bunga (interest rate) memiliki hubungan negatif signifikan dengan harga saham. Sehingga sangat disarankan agar tingkat bunga perlu dikendalikan oleh pihak pemerintah guna meningkatkan keuntungan bagi perdagangan saham sebuah negara lewat peningkatan permintaan dari investor dalam pasar saham, dan meningkatkan penawaran investasi dari emiten pasar modal. Tachiwou (2010), dalam penelitiannya menemukan bahwa pengembangan pasar saham secara positif memiliki pengaruh pertumbuhan ekonomi di Afrika Barat baik dalam jangka waktu pendek maupun jangka waktu panjang.

Barna dan Mura (2010), berpendapat bahwa pasar modal memainkan peran yang sangat penting dalam pengembangan ekonomi. Lebih lanjut mereka berpendapat bahwa, pasar modal yang berfungsi dengan baik akan menjamin emiten dan investor untuk mendapatkan harga yang wajar atas nilai sekuritasnya. Dan dalam hasil penelitian mereka, ditemukan bahwa pengembangan atas pasar modal memiliki hubungan yang positif dengan pertumbuhan ekonomi, disertai dengan efek timbal balik.

Shahbaz et. al. (2008), berpendapat bahwa, keadaan perekonomian pada negara-negara berkembang akan mengalami perubahan yang drastis seiring dengan perubahan ekonomi dunia. Hal ini disebabkan karena adanya aliran modal asing yang masuk karena ekspansi investasi modal asing. Investasi modal asing (foreign direct investment) dan melonjaknya pasar saham adalah indikator dari perubahan ekonomi dunia. Berbeda dengan masa sebelumnya, dimana negara-negara berkembang menghadapi masalah likuiditas yang berarti akan menghadapi masalah pertumbuhan ekonomi. Lebih lanjut dalam penelitian mereka, menemukan bahwa terdapat hubungan yang sangat kuat antara perkembangan pasar saham dengan pertumbuhan ekonomi sebuah negara.

\subsection{Kinerja Keuangan dan Harga Saham.}

Dalam konteks pasar modal, khususnya untuk pasar saham, kinerja dari sebuah emiten dalam sektor industri sangat berperan penting agar menarik perhatian dan kepercayaan investor dalam emiten tersebut. Beberapa sudut pandang yang dapat menjadi minat perhatian dari investor adalah dari siklus bisnis emiten yang merupakan keberlanjutan usaha dari emiten tersebut, kapasitas hutang yang merupakan penggerak operasional emiten selain modal sendiri yang akan membantu menciptakan profit, profitabilitas yang merupakan capaian akhir sebuah emiten yang akan memberikan pengembalian atas modal dan aktiva 
tetap yang merupakan investasi emiten, serta nilai pasar yang merupakan penilaian akhir dari investor atas saham yang beredar dari emiten tersebut.

\section{Siklus Bisnis (Business Cycle).}

Menurut Bodie (2005), salah satu faktor yang akan menentukan sensitivitas laba perusahaan terhadap siklus bisnis, yaitu Operating Leverage. Dimana, Operating Leverage, terkait dengan pembagian biaya variabel dan biaya tetap. Perusahaan dengan biaya tetap yang tinggi akan memiliki operating leverage yang tinggi juga, sehingga goncangan yang kecil pada kondisi bisnis akan memiliki dampak yang besar terhadap profitabilitinya.

Bodie (2005) berpendapat, bahwa investor tidak harus selalu melihat industri yang memiliki sensitivitas yang rendah atas siklus bisnis. Perusahaan yang sangat sensitif dalam industrinya akan mempunyai beta saham yang tinggi dan sangat beresiko, yang mempunyai tingkat pengembalian yang cenderung menurun tapi juga bisa mempunyai kecenderungan untuk bergerak naik, sehingga bergantung pada investor untuk menentukan investasi dengan mempertimbangkan apakah pengembalian atas investasi mempunyai kompensasi yang wajar dengan risikonya.

2. Kapasitas Hutang (Debt Capacity).

Menurut Ross (2005), kapasitas hutang akan identik terkait dengan permasalahan arus kas apabila beban hutang perusahaan tidak dapat ditutupi oleh kas yang tersedia. Kemampuan perusahaan untuk menutupi bunga hutang akan akan sangat diperhitungkan, hal ini disebabkan karena adanya hutang yang tinggi dari perusahaan, akan menimbulkan kemungkinan yang besar dalam hal ketidakmampuan membayar hutang dan masalah keuangan yang serius.

Ross (2005) juga menyatakan bahwa ketika manager perusahaan mempunyai informasi khusus atas kemungkinan munculnya masalah keuangan atas hutang, maka perusahaan akan cenderung untuk meningkatkan modal lewat saham daripada hutang. Jika dugaan ini muncul dalam pasar, maka harga saham akan jatuh pada saat pengumuman penjualan saham.

3. Profitabilitas (Profitability).

Menurut Ross (2005), salah satu atribut dari perusahaan yang sangat sulit diukur dan dikonseptualkan adalah profitabilitas. Tidak ada metode yang begitu jelas untuk mengetahui kapan waktunya sebuah perusahaan mengalami profit.

Pendapat ini didukung oleh Weston (2001) yang mengatakan bahwa harga saham dipengaruhi oleh proyeksi laba per lembar saham (EPS), saat diperoleh laba (ROE), dan PER. Hal ini menjadi pertimbangan investor bahwa mereka tidak akan mengalami kerugian setelah melihat aspek kinerja keuangan perusahaan.

Jones (2004) berpendapat, kombinasi yang berbeda dari rasio keuangan dapat digunakan untuk mendekomposisi ROE, dimana salah satu komponen utama adalah Return On Assets (ROA), sehingga ROE dapat dinyatakan sebagai berikut :

\section{ROE $=$ ROA $x$ Leverage}

Menurut Jones (2004), dengan mengesampingkan hal-hal yang terkait dengan skandal akuntansi, EPS masih merupakan variabel utama yang menarik dari sebagian besar investor. Menurut Weston (2001), salah satu faktor yang mempengaruhi harga saham adalah laba per lembar saham (Earning Per Share/EPS) dimana seorang investor yang melakukan investasi pada perusahaan akan menerima laba atas saham yang dimilikinya. Semakin tinggi laba per lembar saham (EPS) yang diberikan perusahaan akan memberikan pengembalian yang cukup baik. 


\section{Nilai Pasar (Market Value).}

Menurut Ross (2005), salah satu karakteristik perusahaan yang sangat penting dan tidak dapat ditemukan dalam laporan akuntansi adalah nilai pasar (market value) dan istilah "nilai pasar wajar (fair market value)" dapat digunakan untuk menggambarkan harga pasar (market prices).

Menurut Jones (2004), PER dapat merujuk pada earnings multiplier, yang dihitung sebagai rasio dari harga pasar sekarang pada laba perusahaan, dengan mempertimbangkan data historis, data sekarang, dan data estimasi.

Kajian lebih lanjut tentang PER oleh Dreman (2000), menyatakan bahwa,

"In the specific case of out-of-favor stocks (measured by low P/E), the "best" (high $P / E$ ) and the "worst" (low P/E) stocks have an asymmetric response to earnings surprises. On average, surprises as a whole send low P/E stocks sharply higher and high P/E stocks sharply lower relative to the market."

\section{Tujuan Dan Manfaat Penelitian}

\subsection{Tujuan Penelitian}

Tujuan dalam penelitian ini adalah :

1. Untuk mengetahui pengaruh siklus bisnis terhadap reaksi pasar saham.

2. Untuk mengetahui pengaruh kapasitas utang terhadap reaksi pasar saham.

3. Untuk mengetahui pengaruh profitabilitas terhadap reaksi pasar saham.

4. Untuk mengetahui pengaruh nilai pasar terhadap reaksi pasar saham.

\subsection{Manfaat Penelitian.}

Manfaat yang dapat diperoleh dalam penelitian ini adalah :

1. Bagi peneliti, dapat mengaplikasikan ilmu dalam bentuk teoritis ke dalam hal-hal praktis.

2. Bagi masyarakat umum, penelitian ini dapat menjadi bagian untuk menambah wawasan ilmu pengetahuan.

3. Bagi masyarakat intelektual, penelitian ini diharapkan dapat menjadi salah satu referensi untuk penelitian sejenis selanjutnya.

\section{Metode Penelitian}

Populasi dalam penelitian ini adalah 459 perusahaan yang terdaftar sebagai emiten di Bursa Efek Indonesia (BEI) untuk periode tahun 2009 - 2012. Berdasarkan populasi, maka sampel yang diambil adalah 36 perusahaan yang bergerak di sektor industri dengan total pengamatan adalah 144 sampel pengamatan. Menurut Hair (2010), data dalam analisis regresi berganda sebaiknya berada di rentang data 50 - 100 sampel pengamatan.

Metode analisis untuk pengujian hipotesis dalam penelitian ini menggunakan analisis regresi berganda dengan bantuan software SPSS 15.0, dengan $\alpha=5 \%$. Persamaan yang digunakan adalah :

\section{Harga Saham $=a+\beta_{1} \mathrm{DOL}+\boldsymbol{\beta}_{2} \mathrm{DER}+\boldsymbol{B}_{3} \mathrm{ROE}+\boldsymbol{\beta}_{4} \mathrm{PER}$}

Agar model regresi dapat menghasilkan estimator yang baik (Best Linier Unbiased Estimator) maka perlu dilakukan pengujian asumsi klasik sebagai berikut :

\section{Uji Normalitas.}

Menurut Ghozali (2006), uji normalitas bertujuan untuk menguji variabel pengganggu atau residual memiliki distribusi normal. Uji yang dapat digunakan adalah uji statistik non parametrik Kolmogorov Smirnov. 


\section{Uji Autokorelasi.}

Menurut Ghozali (2006), uji autokorelasi bertujuan menguji apakah dalam model regresi linear ada korelasi antara kesalahan pengganggu pada periode $\mathrm{t}$ dengan kesalahan pengganggu pada periode sebelumnya. Menurut Trihendradi (2007), untuk mengetahui adanya korelasi digunakan uji Durbin Watson, yaitu :

1. Jika $1.65<\mathrm{DW}<2.35$ maka tidak terjadi autokorelasi.

2. Jika DW < 1.21 atau DW $>2.79$ maka terjadi autokorelasi.

3. Jika $1.21<\mathrm{DW}<1.65$ atau $2.35<\mathrm{DW}<2.79$, tidak dapat disimpulkan terjadi autokorelasi atau tidak.

3. Uji Multikolinearitas.

Uji multikolinearitas dilakukan untuk menguji apakah model regresi berganda ditemukan adanya korelasi antar variable bebas. Menurut Sarwoko (2005), variance inflation factor (VIF) yang melebihi 10 dapat dikatakan sebagai multikolinearitas yang sangat berat.

\section{Uji Heteroskedastisitas.}

Menurut Ghozali (2006), pengujian ini bertujuan menguji apakah dalam model regresi terjadi ketidaksamaan varians dari residual satu pengamatan ke pengamatan yang lain atau homoskedastisitas. Salah satu metode untuk menguji adanya heteroskedastisitas adalah dengan menggunakan uji Glesjer.

\section{Hasil dan Pembahasan}

\subsection{Statistik Deskriptif.}

Hasil analisis atas statistik deskriptif dari 36 perusahaan selama periode 2009-2012 atau berjumlah 144 total sampel observasi dapat diuraikan dengan menggunakan bantuan program SPSS sebagai berikut :

Tabel 1

Descriptive Statistics

\begin{tabular}{|l|r|r|r|r|r|}
\hline & \multicolumn{1}{|c|}{ N } & \multicolumn{1}{|c|}{ Minimum } & Maximum & \multicolumn{1}{c|}{ Mean } & Std. Deviation \\
\hline Harga_Saham & 144 & 43.00 & 50750.00 & 3671.0833 & 8138.10444 \\
DOL & 144 & -711.17 & 683.70 & 3.8433 & 96.05119 \\
DER & 144 & -4.41 & 64.05 & 2.6101 & 7.97601 \\
ROE & 144 & -8.33 & .74 & -.0692 & 1.02217 \\
PER & 144 & -482.37 & 1065.32 & 4.8081 & 129.00928 \\
Valid N (listw ise) & 144 & & & & \\
\hline
\end{tabular}

\subsection{Uji Asumsi Klasik}

1. Uji Normalitas.

Tabel 2

Tests of Normality

\begin{tabular}{|l|c|c|c|c|c|c|}
\hline & \multicolumn{3}{|c|}{ Kolmogorov-Smirnov ${ }^{\mathrm{a}}$} & \multicolumn{3}{c|}{ Shapiro-Wilk } \\
\cline { 2 - 7 } & Statistic & df & Sig. & Statistic & df & Sig. \\
\hline Unstandardized Res idual & .062 & 144 & $.200^{\star}$ & .982 & 144 & .055 \\
\hline
\end{tabular}
*. This is a low er bound of the true signific ance.
a. Lilliefors Significance Correction

Berdasarkan Uji Normalitas dengan menggunakan Uji Kolmogorov Smirnov, dapat terlihat bahwa tingkat signifikansi berada diatas 0.05 atau sebesar 0.200 yang merupakan nilai terbaik dari uji ini. Sehingga berdasarkan uji normalitas, maka dapat disimpulkan bahwa, residual error dari data adalah terdistribusi dengan normal. 


\section{Uji Autokorelasi.}

Tabel 3

Model Summarl

\begin{tabular}{|l|c|}
\hline Model & $\begin{array}{c}\text { Durbin- } \\
\text { Watson }\end{array}$ \\
\hline 1 & $2.087^{\mathrm{a}}$ \\
\hline
\end{tabular}

a. Predictors: (Constant), PER, DOL, DER, ROE

b. Dependent Variable: HS

Dengan menggunakan angka Durbin Watson, maka diperoleh nilai 2.087 yang berada dalam rentang 1.65 sampai dengan 2.35, sehingga dapat disimpulkan bahwa data-data penelitian tidak memiliki efek autokorelasi.

\section{Uji Multikolinearitas.}

\section{Tabel 4}

\section{Coefficients}

\begin{tabular}{|ll|r|r|}
\hline \multirow{2}{*}{ Model } & \multicolumn{2}{|c|}{ Collinearity } & Statistics \\
\cline { 3 - 4 } & & Tolerance & V IF \\
\hline & DOL & .995 & 1.005 \\
& DER & .984 & 1.016 \\
& ROE & .695 & 1.438 \\
& PER & .693 & 1.442 \\
\hline
\end{tabular}

a. Dependent Variable: Harga_Saham

Dengan menggunakan nilai Variance Inflation Factors (VIF) dibawah dari 10, maka dapat disimpulkan bahwa antara variabel independen tidak terjadi efek multikolinearitas.

\section{Uji Heteroskedastisitas.}

Dengan menggunakan Uji Glesjer, maka hasil pengujian heteroskedastisitas, akan menunjukkan hasil sebagai berikut :

Tabel 5

Coefficients

\begin{tabular}{|c|c|c|c|c|c|c|}
\hline \multirow[b]{2}{*}{ Mod } & & \multicolumn{2}{|c|}{$\begin{array}{c}\text { Unstandardized } \\
\text { Coefficients }\end{array}$} & \multirow{2}{*}{$\begin{array}{c}\begin{array}{c}\text { Standardized } \\
\text { Coefficients }\end{array} \\
\text { Beta }\end{array}$} & \multirow[b]{2}{*}{$t$} & \multirow[b]{2}{*}{ Sig. } \\
\hline & & B & Std. Error & & & \\
\hline \multirow[t]{5}{*}{1} & (Constant) & 1.196 & .231 & & 5.168 & .000 \\
\hline & DOL & -.015 & .054 & -.023 & -.279 & .781 \\
\hline & DER & .039 & .044 & .074 & .881 & .380 \\
\hline & ROE & .202 & .092 & .218 & 2. 192 & .030 \\
\hline & PER & .161 & .088 & .183 & 1.834 & .069 \\
\hline
\end{tabular}

Berdasarkan hasil pengujian, nilai ROE masih menunjukkan tingkat signifikansi dibawah 0.05 sehingga dapat disimpulkan bahwa varians data penelitian masih mengalami efek heteroskedastisitas.

Untuk memperbaiki hal ini, maka pengujian atas heteroskedastisitas akan menggunakan Uji Park yang menguji nilai logaritma atas nilai residual error data, yang menunjukkan hasil sebagai berikut :

Tabel 6

Coefficients

\begin{tabular}{|c|c|c|c|c|c|c|}
\hline \multirow[b]{2}{*}{ Mod } & & \multicolumn{2}{|c|}{$\begin{array}{l}\text { Unstandardized } \\
\text { Coefficients }\end{array}$} & \multirow{2}{*}{$\begin{array}{c}\text { Standardized } \\
\text { Coefficients } \\
\text { Beta }\end{array}$} & \multirow[b]{2}{*}{$t$} & \multirow[b]{2}{*}{ Sig. } \\
\hline & & B & Std. Error & & & \\
\hline \multirow[t]{5}{*}{1} & (Constant) & -.368 & .651 & & -.564 & .573 \\
\hline & DOL & .024 & . 153 & .013 & 156 & .877 \\
\hline & DER & .165 & .125 & .111 & 1.322 & .188 \\
\hline & ROE & .411 & .259 & .159 & 1.586 & .115 \\
\hline & PER & .284 & .247 & .115 & 1.150 & .252 \\
\hline
\end{tabular}


Dengan menggunakan Uji Park, maka dapat terlihat bahwa semua variabel independen memiliki tingkat signifikansi diatas 0.05 terhadap nilai logaritma residual error data, sehingga dapat disimpulkan bahwa, varians data penelitian bebas efek heteroskedastisitas.

\subsection{Pembahasan.}

\subsubsection{Uji Simultan.}

Berdasarkan Tabel 7, diketahui bahwa, secara bersama-sama, rasio harga pasar atas laba (price earnings ratio - PER), siklus bisnis (degree of operating ratio - DOL), kapasitas utang (debt equity ratio - DER), dan profitabilitas (return on equity - ROE) memiliki pengaruh signifikan terhadap harga pasar saham. Hasil ini dapat dilihat dengan ditemukannya Uji $F$ yang memiliki signifikansi dibawah 5\%.

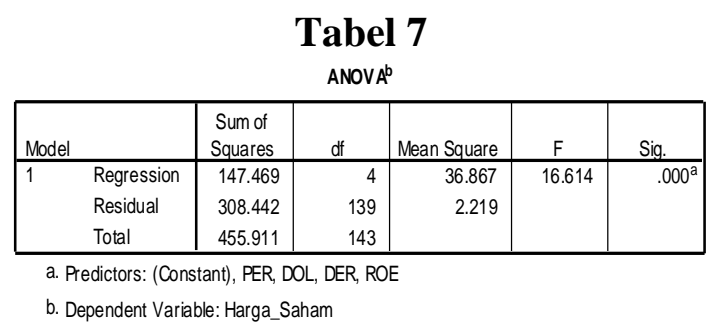

\subsubsection{Koefisien Korelasi dan Determinasi.}

Berdasarkan Tabel 8, hasil analisis menunjukkan bahwa, hubungan antara variabel dependen dengan variabel-variabel independen adalah sebesar 0.569 atau hubungan yang cukup sedang. Sedangkan koefisien determinasi sebesar 0.323 atau model variabel independen dapat menjelaskan model variabel dependen sebesar $32.3 \%$ dan sisanya dijelaskan oleh variabel lain yang tidak dimasukkan dalam penelitian ini.

Tabel 8

Model Summ ary

\begin{tabular}{|l|c|c|c|r|}
\hline Model & $\mathrm{R}$ & R Square & $\begin{array}{c}\text { Adjusted } \\
\text { R Square }\end{array}$ & $\begin{array}{r}\text { Std. Error of } \\
\text { the Estimate }\end{array}$ \\
\hline 1 & $.569^{\mathrm{a}}$ & .323 & .304 & 1.48963 \\
\hline
\end{tabular}

a. Predictors: (Constant), PER, DOL, DER, ROE

\subsubsection{Uji Hipotesis.}

Berdasarkan Tabel 9, dapat diketahui bahwa persamaan regresi berganda bagi harga pasar saham adalah :

\section{Harga Saham $=6.956-0.004 \mathrm{DOL}-0.186 \mathrm{DER}+1.228 \mathrm{ROE}+$ 0.775PER}

\section{Uji Hipotesis 1.}

Siklus bisnis (degree of operating ratio - DOL) memiliki koefisien -0.004 yang memiliki arti bahwa, setiap kenaikan siklus bisnis yang identik dengan risiko bisnis, maka harga pasar saham sebuah entitas akan mengalami penurunan. Akan tetapi, variabel ini memiliki signifikansi diatas 5\% atau sebesar 0.970, sehingga dapat dinyatakan bahwa, secara parsial variabel ini tidak memiliki pengaruh signifikan terhadap harga pasar saham.

\section{Uji Hipotesis 2.}

Kapasitas utang (debt equity ratio - DER) memiliki koefisien -0.186 yang memiliki arti bahwa, setiap kenaikan kapasitas utang yang identik dengan struktur modal, maka harga pasar saham sebuah entitas akan mengalami penurunan. Variabel ini memiliki signifikansi dibawah 
5\% atau sebesar 0.021 , sehingga dapat dinyatakan bahwa, secara parsial variabel ini memiliki pengaruh signifikan terhadap harga pasar saham.

\section{Uji Hipotesis 3.}

Profitabilitas (return on equity - ROE) memiliki koefisien 1.228 yang memiliki arti bahwa, setiap kenaikan profitabilitas atau dalam hal ini tingkat pengembalian ekuitas, maka harga pasar saham sebuah entitas akan mengalami kenaikan, hal ini disebabkan karena investor melihat adanya kenaikan laba pada sebuah entitas yang berarti memberikan jaminan prospek yang baik. Variabel ini memiliki signifikansi dibawah 5\% atau sebesar 0.000 , sehingga dapat dinyatakan bahwa, secara parsial variabel ini memiliki pengaruh signifikan terhadap harga pasar saham.

\section{Uji Hipotesis 4.}

Rasio harga pasar atas laba (price earnings ratio - PER) memiliki koefisien 0.775 yang memiliki arti bahwa, setiap kenaikan rasio pasar atau dalam hal ini terkait dengan penilaian investor, maka harga pasar saham sebuah entitas akan mengalami kenaikan. Variabel ini memiliki signifikansi dibawah 5\% atau sebesar 0.000, sehingga dapat dinyatakan bahwa, secara parsial variabel ini memiliki pengaruh signifikan terhadap harga pasar saham.

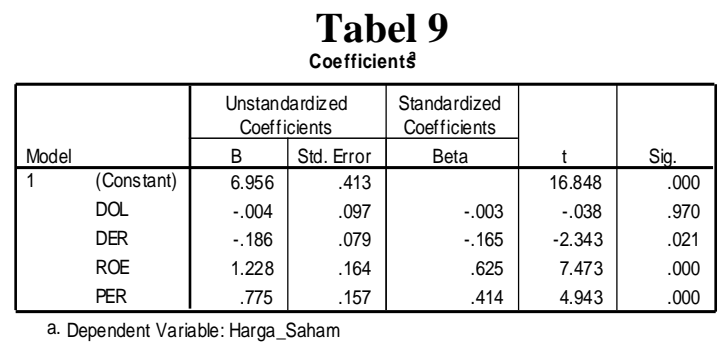

\section{Kesimpulan Dan Saran}

6.1. Kesimpulan.

Berdasarkan hasil analisis, maka penelitian ini dapat disimpulkan sebagai berikut :

1. Siklus bisnis tidak memiliki pengaruh signifikan terhadap harga pasar saham.

2. Kapasitas utang memiliki pengaruh signifikan terhadap harga pasar saham.

3. Profitabilitas memiliki pengaruh signifikan terhadap harga pasar saham.

4. Rasio harga pasar saham atas laba entitas memiliki pengaruh signifikan terhadap harga pasar saham.

\subsection{Saran.}

Penelitian ini memberikan gambaran bahwa, pasar modal di Indonesia masih mengalami pertumbuhan yang baik. Secara teknis, disarankan agar para investor dapat memilih investasinya dalam saham-saham yang memiliki siklus bisnis yang baik, kapasitas utang yang wajar, profitabilitas yang cukup tinggi, dan nilai pasar yang cukup tinggi pula, agar tingkat pengembalian investasi dari para investor dapat memberikan pengembalian yang cukup optimal bagi investor tersebut.

\section{DAFTAR PUSTAKA}

Alam, Mahmudul \& Udin, Gazi Salah. 2009. Relationship between Interest Rate and Stock Price : Empirical Evidence from Developed and Developing Countries. International Journal of Business and Management, Vol. 4 No. 3.

Barna, Flavia \& Mura, Petru-Ovidiu. 2010. Capital Market Development and Economic Growth : The Case Of Romania. Annals of the University of Petroşani, Economics, $10(2), 31-42$ 
Bodie, Zvi. Kane and Marcus. 2005. Investments. Sixth Edition. Mc Graw Hill Companies, Inc. America.

Boubakari, Ake \& Jin, Dehuan. 2010. The Role of Stock Market Development in Economic Growth: Evidence from Some Euronext Countries. International Journal of Financial Research. Volume 1, No. 1, December.

Caporale et. al. 2004. Stock Market Development and Economic Growth : The Causal Linkage. Journal of Economic Development, Volume 29, Number 1, June 2004.

Dreman, David \& Eric A. Lufkin. 2000. Investor Overreaction: Evidence That Its Basis Is Psychological. The Journal of Psychology and Financial Markets Vol. 1, No. 1.

Duca, Gevit. 2007. The Relationship Between the Stock Market and the Economy : Experience From International Financial Markets. Bank of Valletta Review, No. 36, Autumn.

Ghozali, Imam. 2006. Aplikasi Analisis Multivariate dengan Program SPSS. Badan Penerbit Universitas Diponegoro. Semarang.

Jones, P. Charles. 2004. Investments: Analysis and Management. Ninth Edition. John Wiley \& Sons, Inc. America.

Ogboi \& Oladipo. 2012. Stock Market and Economic Growth: The Nigerian Experience. Research Journal of Finance and Accounting ISSN 2222-1697 (Paper) ISSN 2222-2847 (Online) Vol 3, No 4.

Pontoh, Winston. 2011. Pengaruh Siklus Bisnis, Kapasitas Hutang, Profitabilitas dan Nilai Pasar terhadap Reaksi pada Perusahaan Manufaktur di Bursa Efek Indonesia. Media Riset Akuntansi, Auditing, dan Informasi Lembaga Penerbit Fakultas Ekonomi Universitas Trisakti Jakarta, Nomor 1 / Volume 11, April.

Riman et. al. 2008. Stock Market Performance and Economic Growth in Nigeria : A Casuality Investigation. Global Journal of Social Sciences, Vol. 7 No. 2.

Ross, Stephen A. Westerfield and Jaffe. 2005. Corporate Finance. Seventh Edition. Mc Graw Hill Companies. America.

Shahbaz, Muhammad et al. 2008. Stock Market Development and Economic Growth: ARDL Causality in Pakistan. International Research Journal of Finance and Economics ISSN 1450-2887 Issue 14.

Sharma. 2013. Impact of Economic Growth on Stock Market Performance. Asian Journal of Multidimensional Research Vol.2 Issue 5, May 2013, ISSN 2278-4853.

Tachiwou. 2010. Stock Market Development and Economic Growth : The Case of West African Monetary Union. International Journal of Economics and Finance Vol. 2, No. 3; August.

Trihendradi, Cornelius. 2007. Kupas Tuntas Analisa Regresi. Penerbit ANDI Yogyakarta.

Weston, Brigham F.Eugene \& J. F. Houston, 2001, Manajemen Keuangan Edisi 8. Penerbit Erlangga. Jakarta. 